\title{
Effect of Oleylamine Concentration and Operating Conditions on Ternary Nanocatalyst for Fischer-Tropsch Synthesis Using Response Surface Methodology
}

\author{
Tahereh Taherzadeh Lari ${ }^{1, ~ *}$, Hamid Reza Bozorgzadeh², Hossein Atashi, \\ Abdol Mahmood Davarpanah ${ }^{4}$, Ali Akbar Mirzaei ${ }^{1}$ \\ ${ }^{1}$ Department of Chemistry, Faculty of Science, University of Sistan and Baluchestan, Zahedan, Iran \\ ${ }^{2}$ Catalyst Division, Research Institute of Petroleum Industry (RIPI), Tehran, Iran \\ ${ }^{3}$ Department of Chemical Engineering, Faculty of Engineering, University of Sistan and Baluchestan, Zahedan, Iran \\ ${ }^{4}$ Department of Physics, Faculty of Science, University of Sistan and Baluchestan, Zahedan, Iran
}

Email address:

lari.tahereh@gmail.com (T. T. Lari),tzd.tahereh@yahoo.com (T. T. Lari)

${ }^{*}$ Corresponding author

\section{To cite this article:}

Tahereh Taherzadeh Lari, Hamid Reza Bozorgzadeh, Hossein Atashi, Abdol Mahmood Davarpanah, Ali Akbar Mirzaei. Effect of Oleylamine Concentration and Operating Conditions on Ternary Nanocatalyst for Fischer-Tropsch Synthesis Using Response Surface Methodology. American Journal of Chemical Engineering. Vol. 7, No. 2, 2019, pp. 71-80. doi: 10.11648/j.ajche.20190702.13

Received: May 29, 2019; Accepted: July 1, 2019; Published: July 12, 2019

\begin{abstract}
The Fe-Co-Ce nanocatalyst was synthesized by a solvothermal method and used in Fischer-Tropsch synthesis. This paper represents a statistical analysis to illustrate the effects of oleylamine concentration and operating variables (temperature, pressure, inlet $\mathrm{H}_{2} / \mathrm{CO}$ molar ratio) on light olefin $\left(\mathrm{C}_{2}{ }^{-}-\mathrm{C}_{4}{ }^{-}\right)$, paraffin $\left(\mathrm{C}_{1}+\mathrm{C}_{2}-\mathrm{C}_{4}\right)$ selectivity and $\mathrm{CO}$ conversion (catalyst activity) in a fixed bed micro reactor was done. In order to evaluate variable effects, analysis of variance (ANOVA) was applied for modeling and optimization of goal products using response surface methodology (RSM). The result showed that by increasing both amine concentration and pressure at lower temperature and inlet $\mathrm{H}_{2} / \mathrm{CO}$ molar ratio, olefin selectivity and $\mathrm{CO}$ conversion rises, while paraffin selectivity reduces. Comparison of optimization results to maximum olefin selectivity and $\mathrm{CO}$ conversion and minimum paraffin selectivity for predicted and experimental data indicate a desirable agreement.
\end{abstract}

Keywords: Fischer-Tropsch Synthesis, Response Surface Methodology, Optimization, Fe-Co-Ce Nanocatalyst, Oleylamine Concentration, Operating Conditions

\section{Introduction}

In the near future the feedstock of chemical industry will shift from crude oil to natural gas because of the limited reserves of crude oil and increasing environmental constraints. Fischer-Tropsch synthesis is a promising process, is known as an exothermic polymerization reaction, which converts $\mathrm{CO}$ and $\mathrm{H}_{2}$ into water and linear hydrocarbons (chemical liquefaction of natural gas) $[1,2]$. The main active industrially metals for Fischer-Tropsch catalysts are based on iron and cobalt. The price for iron-based catalysts is low, but these catalysts suffer from a low wax selectivity, deactivation and inhibition of productivity by water at high syngas conversions. However, cobalt-based catalysts are stable, promoting formation of heavy wax and permit high syngas conversions $[3,4]$. Rare earth oxides have been extensively illustrated as both structural and electronic promoters to boost catalyst features. Among rare earth elements, $\mathrm{CeO}_{2}$ is the most prominent metal oxide in industrial catalysis process. The activity of $\mathrm{CeO}_{2}$ as a promoter has some controversy viewpoint [5]. Solid catalysts are highly complicated products derived from chemicals by various procedures.

The catalytic features of heterogeneous catalysts are greatly affected by both every step of fabrication (such as temperature, time, $\mathrm{pH}$, pressure and concentration) and operating conditions [6]. Solvothermal synthesis is comprises of heating of solvents and metal compounds, which coordinated in attendance of an organic capping agent at high temperatures. This method included commonly three steps: (i) 
dissociation of metal precursors occurs by heating of solution; (ii) for further particle nucleation and growth, the solution aged at desired temperature and (iii) separation of particles from solvent and unreacted material [7]. Compared to other synthetic methods, it has the additional advantages of simplicity, high reaction speed, and significant superiority of synthesis under moderate reaction conditions. Moreover, it allows for different solvents and surface agents to be appropriately selected. Application of a surfactant like Oleylamine, which is a primary amine with a long chain, has the most efficient ability to act as a solvent, surfactant, or reducing agent [8]. As well as doing as an electron donor at enhanced temperatures, is sufficient enough to both limiting nanoparticle growths and avoiding accumulation due to forming a significant superficial layer that works as a barrier to mass transfer [9]. Most of studies done according to traditionally experiment, which one variable changed, whereas the others kept fix. Thus it probably cause to incorrect results because of the interaction effects are ignored. Response surface methodology (RSM) is a helpful statistical method to establish functional relationship between several independent variables to response, diagnostic the suitability of the model, evaluate interaction effects and optimizing variable parameters in chemical processes [10].

The significant benefit of using statistical model for product selectivity comparing with the previous studies, which investigates effect of variables without present a model, is depict both the importance of each parameters and also illustrate interaction effects on each other. In this research, $\mathrm{Fe}-$ $\mathrm{Co}-\mathrm{Ce}$ (ternary) nanocatalyst synthesized by solvothermal procedure and catalytic performance towards olefin, paraffin selectivity and $\mathrm{CO}$ conversion were studied. To the best of our knowledge, no similar research has been reported previously on consideration of the relationship between parameters of solvothermal synthesis and operating variables in FischerTropsch synthesis. There are some researches, which studied solvothermal method in order to synthesis catalyst in FTS, but the effect of synthesis parameters did not evaluated [11, 12]. The objective of the present study is illustrate the effect of oleylamine concentrations and operating variables including temperature, pressure, and inlet $\mathrm{H}_{2} / \mathrm{CO}$ molar ratio on catalytic behavior. Investigation of binary, quadratic interactions, analysis of variance, modeling, and optimization were evaluated by RSM.

\section{Experimental}

\subsection{Materials}

All the chemicals were of analytical grade used without further purification. Iron nitrate (II) nona hydrate $\left(\mathrm{Fe}\left(\mathrm{NO}_{3}\right)_{3} .9 \mathrm{H}_{2} \mathrm{O}, 99 \%\right)$, cobalt nitrate (II) hegza hydrate $\left(\mathrm{Co}\left(\mathrm{NO}_{3}\right)_{2} \cdot 6 \mathrm{H}_{2} \mathrm{O}, 99 \%\right)$, cerium nitrate (III) hegza hydrate $\left(\mathrm{Ce}\left(\mathrm{NO}_{3}\right)_{3} \cdot 6 \mathrm{H}_{2} \mathrm{O}, 99 \%\right)$, toluene $\left(\mathrm{C}_{7} \mathrm{H}_{8}, 99 \%\right)$, and ethanol $\left(\mathrm{C}_{2} \mathrm{H}_{5} \mathrm{OH}, 99 \%\right)$ were purchased from Merck. Oleylamine $\left(\mathrm{C}_{18} \mathrm{H}_{37} \mathrm{~N}, 70 \%\right)$ was purchased from Aldrich.

\subsection{Nanocatalyst Synthesis}

Iron-cobalt-cerium three metals were synthesized using the solvothermal method. The preparation method can be described briefly at different concentration of oleylamine performs as follow: $0.5 \mathrm{~g}(1.15 \mathrm{mmol})$ of cerium nitrate, 0.32 $\mathrm{g}(0.91 \mathrm{mmol})$ of cobalt nitrate, $0.38 \mathrm{~g}(0.94 \mathrm{mmol})$ of iron nitrate were add into $50 \mathrm{~mL}$ of toluene containing 5,8 and 10 $\mathrm{g}(20.2,29.9$ and $37.4 \mathrm{mmol})$ of oleylamine. The mixture was magnetically stirred vigorously for $1 \mathrm{~h}$ at room temperature (Figure 1). The resulting mixture solution was subsequently transferred into an $80 \mathrm{~mL}$ Teflon-lined autoclave and heated to $180^{\circ} \mathrm{C}$. The autoclave was sealed and maintained at the given temperature for $18 \mathrm{~h}$ before it was allowed to cool down to room temperature. The nanoparticles formed were precipitated in the excess ethanol and further isolated from each other by centrifugation. The resulting nanoparticles were finally transferred to an oven to be dried before calcination at 100 and $500^{\circ} \mathrm{C}$ in air for $4 \mathrm{~h}$.

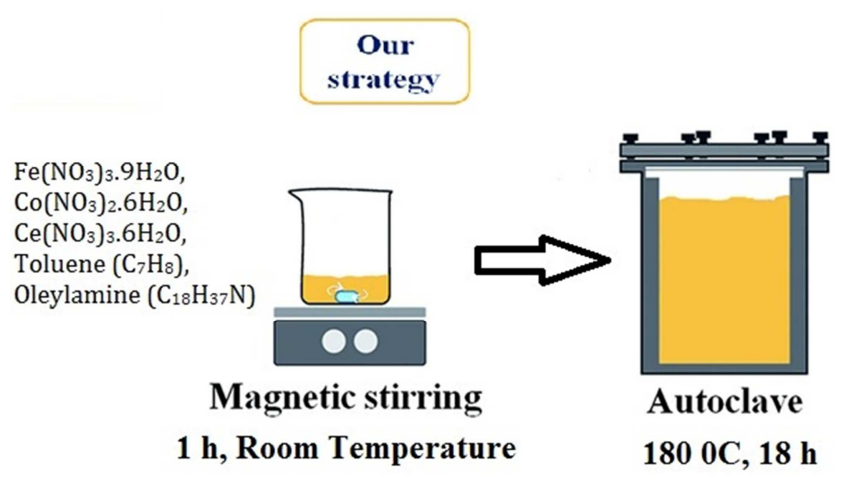

Figure 1. Schematic diagram of the procedure for solvothermally synthesized nanocatalyst.

\subsection{Research Catalytic Setup for Fischer-Tropsch Synthesis Experiments}

Fischer-Tropsch synthesis was performed in a stainless fixed-bed micro reactor with an inner diameter of $12 \mathrm{~mm}$. The catalyst $(1.0 \mathrm{~g})$ was well dispersed with asbestos and loaded in the center of reactor with thermocouple inside. Three mass flow controllers (Model 5850E, Brooks Instrument, Hatfield, PA, USA) were used to automatically adjust the flow rate of the inlet gases containing $\mathrm{CO}, \mathrm{H}_{2}$, and $\mathrm{N}_{2}$ (with $99.99 \%$ purity). A mixture of $\mathrm{CO}$ and $\mathrm{H}_{2}\left(\mathrm{H}_{2} / \mathrm{CO}\right.$ $=1$, flow rate of each gas $30 \mathrm{~mL} \mathrm{~min}^{-1}$ ) was subsequently introduced into the reactor, which was placed inside a tubular furnace (Figure 2 and 3, Model ATU 150-15, Atbin). The reaction temperature was controlled by a digital program controller (DPC) and visually monitored by a computer through a thermocouple inserted into the catalytic bed. The catalyst is situ was pre-reduced under 2-bar pressure and $\mathrm{H}_{2}$ flow (with flow rate of $30 \mathrm{~mL} \mathrm{~min}^{-1}$ ) at $400^{\circ} \mathrm{C}$ for $48 \mathrm{~h}$ before the reaction started. In each test, $1.0 \mathrm{~g}$ of catalyst was loaded and all data was collected after the time of $4 \mathrm{~h}$ to ensure steady state operation was attained. 


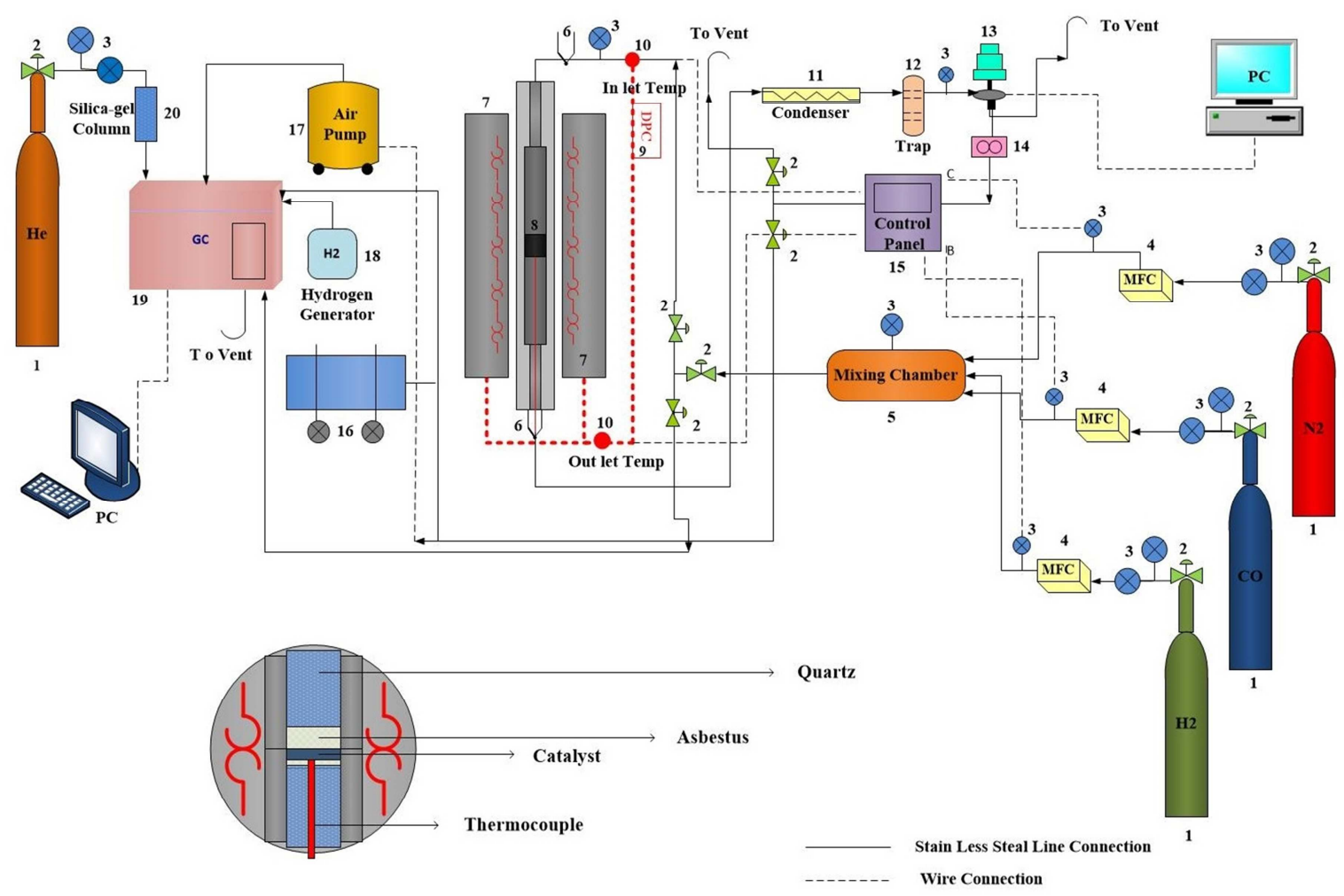

Figure 2. Experimental setup of fixed bed reactor (FBR) for Fischer-Tropsch synthesis over iron-cobalt-cerium mixed oxide nanocatalyst: (1) gas cylinders, (2) valve, (3) pressure gauge, (4) mass flow controller (MFC), (5) mixing chamber, (6) thermocouple, (7) tubular furnace, (8) fix bed reactor and catalyst bed (reaction zone), (9) temperature digital program controller (DPC), (10) resistance temperature detector, (11) condenser, (12) trap, (13) back pressure regulator (BPR), (14) flow meter, (15) control panel, (16) electrical motor, (17) air pump, (18) hydrogen generator, (19) gas chromatograph, (20) silica-gel column.

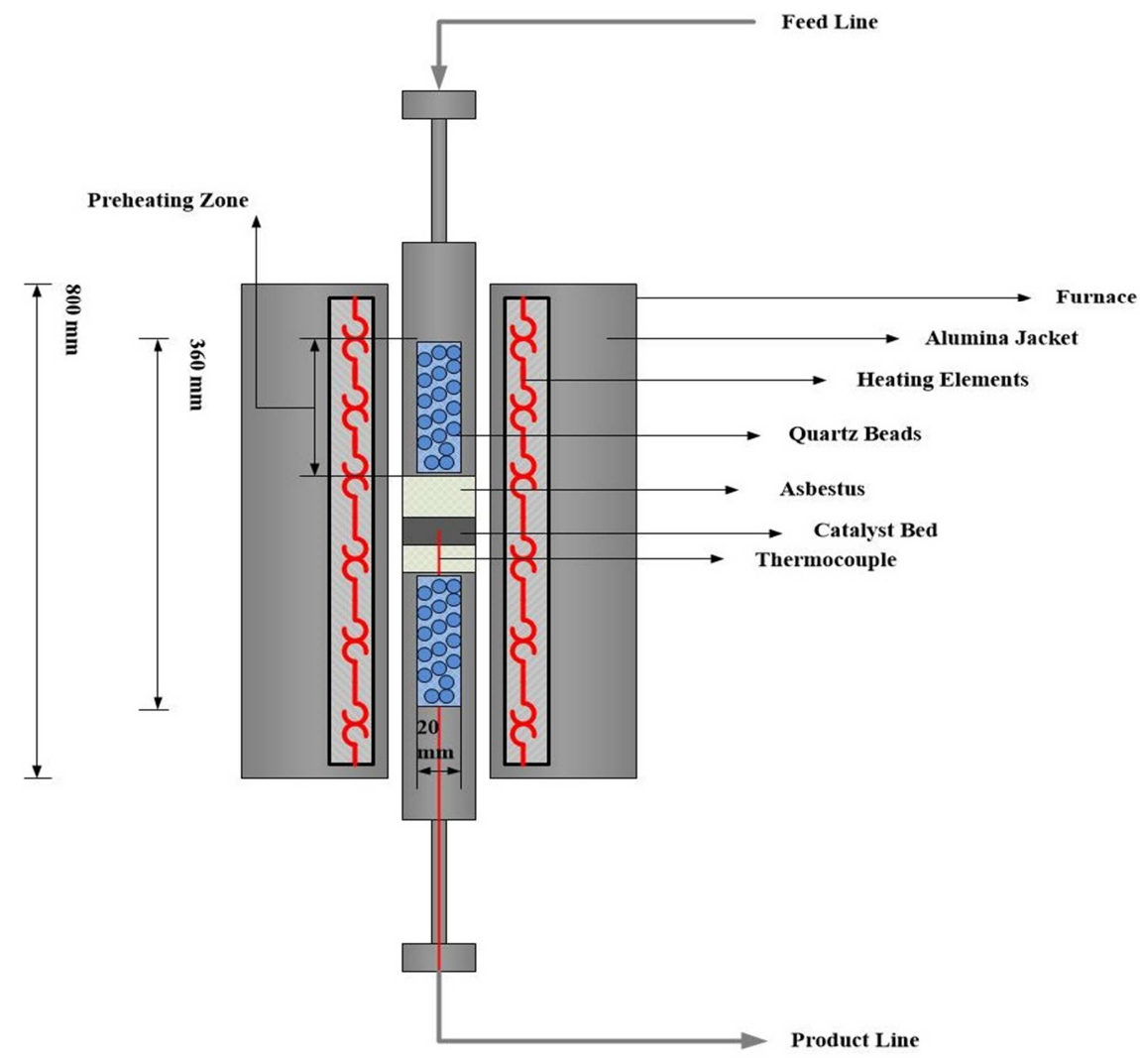

Figure 3. Schematic design of fixed-bed-reactor (FBR). 


\subsection{Catalytic Performance Measurement}

The Fischer-Tropsch synthesis was performed with mixture of $\mathrm{CO}$ and $\mathrm{H}_{2}$, in the temperature range of 270$400^{\circ} \mathrm{C}$, with inlet $\mathrm{H}_{2} / \mathrm{CO}$ molar ratio of $1-4$, the space velocity of $3600 \mathrm{~h}^{-1}$ and at $2-5 \mathrm{bar}$ range of pressure. In each experiment, for reactor catalyst testing at each oleylamine concentration to avoid of deactivation effect, fresh catalyst was loaded. An automatic backpressure regulator in order to adjust and modify the pressure range via the TESCOM software was used. Reactant and product streams were analyzed by online gas chromatography (Thermo ONIX UNICAM PROGC+) equipped with two thermal conductivity detectors (TCD) and one flame ionization detector (FID) with ability to analysis of a broad variety of gaseous hydrocarbon mixtures. One TCD used for the analysis of hydrogen $\left(\mathrm{H}_{2}\right)$ and the other one used for all the permanent gases like $\mathrm{N}_{2}, \mathrm{O}_{2}$ and $\mathrm{CO}$. The analysis of hydrocarbons was done by FID. The analysis of noncondensable gases, methane through $\mathrm{C}_{8}$ hydrocarbons is applied. The contents of the sample loop were injected automatically into an alumina capillary column. As well as helium (He) was employed as a carrier gas for optimum sensitivity. The calibration was performed by various calibration mixtures $\left(\mathrm{CH}_{4}, \mathrm{C}_{2} \mathrm{H}_{4}, \mathrm{C}_{2} \mathrm{H}_{6}, \mathrm{C}_{3} \mathrm{H}_{6}, \mathrm{C}_{3} \mathrm{H}_{8}, \mathrm{n}-\mathrm{C}_{4} \mathrm{H}_{10}\right.$, $\mathrm{i}-\mathrm{C}_{4} \mathrm{H}_{10}, \mathrm{n}-\mathrm{C}_{5} \mathrm{H}_{12}$ ) and pure compounds obtained from Tarkib Gas Alvand Company of Iran. The operation condition and obtained data of each experiment are presented in below Tables. The CO conversion percent calculated according to the normalization method:

$$
\text { CO conversion }(\%)=\frac{(\text { Moles of } \mathrm{CO} \text { in })-(\text { Moles of CO out })}{(\text { Moles of } \mathrm{CO} \text { in })} \times 100(1)
$$

\subsection{Statistical Analysis}

Response surface methodology (RSM) is a set of statistical and mathematical technique to utilize, improve and optimizing a model by affecting on multiple factors using design of experiments (DoE) method and statistical analysis [13]. RSM reduced and simplified experimental designs to obtain an entire understanding of the model. As well as achieved the optimal combination of independent variables instead of looking for the optimal solution among a variety number of randomly created parameters. The advantage of RSM method for optimization than without statistic approach is to design, formulation of products and the most important one is predicting interaction effects of involved factors. The RSM technique can suggest a model according to experimental and predicted data and acquires the most desirable model for response by adjusting the factors.

In this study, RSM method was done using historical data, which achieved by experiment previously. The 35 experiments tested in a fixed-bed micro reactor and used for evaluation, modeling and optimization of independent variables of solvothermaly synthesized nanocatalyst via Fischer-Tropsch synthesis by RSM. The empirical model related to a response and to find out intercept, linear, quadratic and interaction terms was used as follow:

$$
\mathrm{X}=\mathrm{t}_{0}+\sum_{\mathrm{i}=1}^{\mathrm{n}} \mathrm{t}_{\mathrm{i}} \mathrm{Y}_{\mathrm{i}}+\sum_{\mathrm{i}=1}^{\mathrm{n}} \mathrm{t}_{\mathrm{ii}} \mathrm{Y}_{\mathrm{i}}^{2}+\sum_{\mathrm{ij}}^{\mathrm{n}} \mathrm{t}_{\mathrm{ij}} \mathrm{Y}_{\mathrm{i}} \mathrm{Y}_{\mathrm{j}} \pm \mathcal{E}
$$

Where, $\mathrm{X}$ is the predicted response, $\mathrm{Y}_{\mathrm{i}}$ and $\mathrm{Y}_{\mathrm{j}}$ are independent variables, $t_{0}$ is the intercept coefficient, $t_{i}$ represents the linear effect of $Y_{i}, t_{i i}$ is the quadratic effect of $Y_{i}$, and $t_{i j}$ is the interaction terms of $Y_{i}$ and $Y_{j}$, as well as, $n$ observes the number of experiments. The regression terms of a response in order to statistical significant were checked by ANOVA (analysis of variance).

\section{Results and Discussion}

\subsection{Fischer-Tropsch Synthesis Performance}

The activity and selectivity of synthesized nanocatalysts towards products in Fischer-Tropsch synthesis are affected by many operating (e.g. temperature, pressure, inlet $\mathrm{H}_{2} / \mathrm{CO}$, space velocity and etc) and fabricating conditions. In this study, the effects of oleylamine concentration $(\mathrm{N})$, Temperature $(\mathrm{T})$, pressure $(\mathrm{P})$ and inlet $\mathrm{H}_{2} / \mathrm{CO}$ molar ratio (M) on the selectivity of Olefin $\left(\mathrm{C}_{2}{ }^{-}-\mathrm{C}_{4}{ }^{-}\right)$, Paraffins $\left(\mathrm{C}_{1}+\mathrm{C}_{2}{ }^{-}\right.$ $-\mathrm{C}_{4}^{-}$), and catalyst activity ( $\mathrm{CO}$ conversion) at operating condition of $\left(\mathrm{H}_{2} / \mathrm{CO}=1-4, \mathrm{GHSV}=3600 \mathrm{~h}^{-1}, \mathrm{P}=2-5\right.$ bar, $\mathrm{T}=270-400^{\circ} \mathrm{C}$ ) investigated as a model by RSM.

\subsection{Design of Experiments}

RSM design for historical data is used to illustrate both the effect of independent variables and their interactions. The studied variables includes four parameters; A, B, C, D, for amine concentration $(\mathrm{cc})$, temperature $\left({ }^{\circ} \mathrm{C}\right)$, pressure (bar), and inlet $\left(\mathrm{H}_{2} / \mathrm{CO}\right)$ molar ratio named $\mathrm{N}, \mathrm{T}, \mathrm{P}$, and $\mathrm{M}$ respectively. According to achieved 35 experimental data, the studied responses were olefin selectivity $\left(\mathrm{C}_{2}{ }^{\prime \prime}-\mathrm{C}_{4}{ }^{\prime \prime}\right)$, paraffin selectivity $\left(\mathrm{C}_{1}+\mathrm{C}_{2}-\mathrm{C}_{4}\right)$ and $\mathrm{CO}$ conversion as a catalyst activity, which indicated in Table 1. Response surface methodology, analysis of variance (ANOVA), modeling and optimization of responses carried out using Design Expert 7.00 Software.

\begin{tabular}{|c|c|c|c|c|c|c|c|}
\hline \multirow{2}{*}{ Run } & $\mathbf{A}$ & B & C & D & $\mathrm{X}_{1}^{\mathrm{a}}$ & $\mathbf{X}_{2}^{\mathbf{b}}$ & $\mathbf{X}_{3}^{\mathbf{C}}$ \\
\hline & $\mathrm{N}(\mathrm{cc})$ & $\mathbf{T}\left({ }^{\circ} \mathrm{C}\right)$ & $\mathbf{P}$ (bar) & $\mathrm{M}=\mathrm{H} 2 / \mathrm{CO}$ & X Olefin (\%) & X Paraffin (\%) & X CO (\%) \\
\hline 1 & 5 & 270 & 2 & 1 & 19.63 & 52.9 & 52 \\
\hline 2 & 5 & 300 & 2 & 1 & 26.72 & 55.94 & 29.5 \\
\hline 3 & 5 & 330 & 2 & 1 & 30.35 & 59.04 & 36 \\
\hline 4 & 5 & 350 & 2 & 1 & 29.08 & 59.61 & 41.8 \\
\hline 5 & 5 & 380 & 2 & 1 & 23.19 & 61.34 & 45 \\
\hline 6 & 5 & 400 & 2 & 1 & 16.11 & 62.35 & 49.5 \\
\hline
\end{tabular}

Table 1. Experimental data and catalytic performance of Fe-Co-Ce nanocatalyst synthesized by solvothermal method during FTS. 


\begin{tabular}{|c|c|c|c|c|c|c|c|}
\hline \multirow{2}{*}{ Run } & $\mathbf{A}$ & B & C & D & $\mathbf{X}_{1}^{\mathrm{a}}$ & $\mathbf{X}_{2}^{\mathbf{b}}$ & $\mathbf{X}_{3}^{\mathrm{C}}$ \\
\hline & $\mathrm{N}(\mathrm{ccc})$ & $\mathrm{T}\left({ }^{\circ} \mathrm{C}\right)$ & $\mathbf{P}$ (bar) & $\mathrm{M}=\mathrm{H} 2 / \mathrm{CO}$ & X Olefin (\%) & X Paraffin (\%) & X CO (\%) \\
\hline 7 & 8 & 300 & 2 & 1 & 16.28 & 53.69 & 34 \\
\hline 8 & 8 & 330 & 2 & 1 & 21.99 & 60.55 & 37.6 \\
\hline 9 & 8 & 350 & 2 & 1 & 21.93 & 63.34 & 41 \\
\hline 10 & 8 & 380 & 2 & 1 & 18.69 & 69.23 & 53 \\
\hline 11 & 8 & 400 & 2 & 1 & 12.14 & 74.17 & 61 \\
\hline 12 & 10 & 300 & 2 & 1 & 22.62 & 48.82 & 26.6 \\
\hline 13 & 10 & 330 & 2 & 1 & 28.85 & 54.29 & 31.1 \\
\hline 14 & 10 & 350 & 2 & 1 & 26.87 & 60.36 & 35.5 \\
\hline 15 & 10 & 380 & 2 & 1 & 23.88 & 67.36 & 47.7 \\
\hline 16 & 10 & 400 & 2 & 1 & 17.89 & 70.5 & 54 \\
\hline 17 & 5 & 300 & 2 & 1 & 25.38 & 54.4 & 37.5 \\
\hline 18 & 5 & 300 & 4 & 1 & 32.09 & 50.7 & 43 \\
\hline 19 & 5 & 300 & 5 & 1 & 27.97 & 61.6 & 44.8 \\
\hline 20 & 8 & 300 & 3 & 1 & 21.99 & 53.68 & 36.7 \\
\hline 21 & 8 & 300 & 4 & 1 & 22.43 & 56.31 & 52.3 \\
\hline 22 & 8 & 300 & 5 & 1 & 18.01 & 64.31 & 55.9 \\
\hline 23 & 10 & 300 & 2 & 1 & 22.71 & 46 & 29.1 \\
\hline 24 & 10 & 300 & 3 & 1 & 28.85 & 43 & 34 \\
\hline 25 & 10 & 300 & 4 & 1 & 27.9 & 49.44 & 37.5 \\
\hline 26 & 10 & 300 & 5 & 1 & 22.76 & 61.9 & 58.4 \\
\hline 27 & 5 & 300 & 2 & 2 & 29.8 & 54.2 & 32.6 \\
\hline 28 & 5 & 300 & 2 & 3 & 24.34 & 58.5 & 38.4 \\
\hline 29 & 5 & 300 & 2 & 4 & 18.53 & 58.03 & 44.5 \\
\hline 30 & 8 & 300 & 2 & 2 & 21.68 & 66 & 27.9 \\
\hline 31 & 8 & 300 & 2 & 3 & 19.22 & 66.64 & 41.3 \\
\hline 32 & 8 & 300 & 2 & 4 & 14.49 & 70.29 & 48.2 \\
\hline 33 & 10 & 300 & 2 & 2 & 26.35 & 57.83 & 29.5 \\
\hline 34 & 10 & 300 & 2 & 3 & 25.61 & 64.6 & 42.8 \\
\hline 35 & 10 & 300 & 2 & 4 & 22.74 & 68.35 & 54.6 \\
\hline
\end{tabular}

a: olefin selectivity

b: paraffin selectivity

c: co conversion (catalyst activity)

\subsubsection{Statistical Models of Olefin, Paraffin Selectivity and Catalyst Activity}

Analysis of variance was done for all responses. According to the sequential model sum of square test, the linear model suggested as the most suitable model in the case of $X_{1}, X_{2}$ and $X_{3}$ selectivity with $p$-value of $<0.0001$. The significance of regression coefficient verified by P-values, which is not adequate and should be lower than 0.05 . Final encoded models for independent variables in terms of named independent variables are presented in following equations:

$$
\begin{aligned}
\mathrm{X} 1(\%)= & -238.07270-21.57902 \times \mathrm{N}+1.85368 \times \mathrm{T}+17.25144 \times \mathrm{P}+4.73863 \times \mathrm{M}+0.012937 \times \mathrm{N} \times \\
\mathrm{T}+ & 0.54577 \times \mathrm{N} \times \mathrm{M}+1.08507 \times \mathrm{N} 2-2.8874 \times 10-3 \times \mathrm{T} 2-2.44388 \times \mathrm{P} 2-2.05799 \times \mathrm{M} 2(3) \\
\mathrm{X} 2(\%)= & +62.64891+3.65542 \times \mathrm{N}-0.041767 \times \mathrm{T}-23.29887 \times \mathrm{P}-4.10818 \times \mathrm{M}+0.025667 \times \mathrm{N} \times \mathrm{T}+ \\
& 1.11276 \times \mathrm{N} \times \mathrm{M}-0.89904 \times \mathrm{N} 2+3.76699 \times \mathrm{P} 2
\end{aligned}
$$

$\mathrm{X} 3(\%)=+406.51871-7.83548 \times \mathrm{N}-1.99545 \times \mathrm{T}-14.00758 \times \mathrm{P}-20.30212 \times \mathrm{M}+0.032850 \times \mathrm{N} \times \mathrm{T}+1.28708 \times$ $\mathrm{N} \times \mathrm{P}+1.35024 \times \mathrm{N} \times \mathrm{M}-0.53842 \times \mathrm{N} 2+2.80231 \times 10-3 \times \mathrm{T} 2+1.48580 \times \mathrm{P} 2+3.03492 \times \mathrm{M} 2(5)$

The $\mathrm{X}_{3}(\mathrm{CO}$ conversion) was selected as a measure of catalyst activity, while $\mathrm{X}_{1}$ and $\mathrm{X}_{2}$ were chosen as a measure of catalyst selectivity. The analysis of variance (ANOVA) for $\mathrm{X}_{1}$ and $\mathrm{X}_{2}$ selectivity and catalyst activity of $\mathrm{X}_{3}$ are reported in Table 2 . The large F-value includes $88.32,54.62$ and 14.68 for $\mathrm{X}_{1}, \mathrm{X}_{2}$ and $\mathrm{X}_{3}$ respectively imply that the obtained models are significant. Also, the p-value less than $5 \%$ verifies the adequacy of models. Concerning about selectivity model of $\mathrm{X}_{1}$ (olefin); A (amine concentration), B (Temperature), $\mathrm{C}$ (Pressure), D (inlet $\mathrm{H}_{2} / \mathrm{CO}$ molar ratio) and interactions of $\mathrm{AB}, \mathrm{AD}$ and $\mathrm{A}^{2}, \mathrm{~B}^{2}, \mathrm{C}^{2}, \mathrm{D}^{2}$ were significant terms of models. Regarding about $\mathrm{X}_{2}$ (paraffin) response; $\mathrm{A}, \mathrm{B}, \mathrm{C}, \mathrm{D}$ and interactions of $\mathrm{AB}, \mathrm{AD}, \mathrm{A}^{2}$ and $\mathrm{C}^{2}$ were significant terms of obtained model. Similarly, in the case of $\mathrm{X}_{3}$ (CO conversion) response, $\mathrm{A}, \mathrm{B}, \mathrm{C}, \mathrm{D}$ and interactions of $\mathrm{AB}, \mathrm{AC}, \mathrm{AD}, \mathrm{A}^{2}, \mathrm{~B}^{2}, \mathrm{C}^{2}$ and $\mathrm{D}^{2}$ were significant terms. In order to improve the models, insignificant terms with $\mathrm{p}$-value higher than 0.05 were dropped.

Table 2. Analysis of variance reported for evaluation of responses.

\begin{tabular}{lllllllll}
\hline Model & F-value & P-value & df & $\mathbf{R}^{\mathbf{2}}$ & Adj-R $^{\mathbf{2}}$ & Pred-R $^{\mathbf{2}}$ & Adeq Precision $^{\text {Lack of fit }}$ \\
\hline $\mathrm{X}_{1}$ & 88.32 & $<0.0001$ & 10 & 0.9735 & 0.9625 & 0.9439 & 39.461 & 0.3823 \\
$\mathrm{X}_{2}$ & 54.62 & $<0.0001$ & 8 & 0.9438 & 0.9266 & 0.8911 & 27.972 & 0.4600 \\
$\mathrm{X}_{3}$ & 14.68 & $<0.0001$ & 11 & 0.8753 & 0.8157 & 0.6375 & 13.418 & 0.6424 \\
\hline
\end{tabular}


Since "Lack of fit" is an undesirable characteristic of a model, the non-significant value (greater than 0.1 ) of lack of fit is good. All responses have insignificant p-value to their lack of fit as indicated in Table 2. The differences between "Pred R-Squared" and "Adj R-Squared" have to be (less than 0.2 ) so all responses are in reasonable agreement, which shows that the obtained models predict the responses precisely. The actual values versus predicted values are plotted in Figure 4. All responses indicate a good correlation between actual and predicted values. "Adeq Precision" measures signal to noise ratio, so a ratio greater than 4 is desirable which indicates an adequate signal. As reported in Table 2 Adeq Precision of 39.461, 27.972 and 13.418 for $\mathrm{X}_{1}$, $\mathrm{X}_{2}$ selectivity and $\mathrm{X}_{3}$ activity are high enough and indicate an adequate design, so these models can be used to navigate the design space.

The accuracy of achieved models determines by both $\mathrm{R}$ Square and evaluation of correlation coefficients between RSquare and R-Square Adjust, which the nearer to the 1 the better. Desirable value of R-Square achieves by adding or reducing terms of models. R-Square Adjust is attributed to an unbiased assessment.
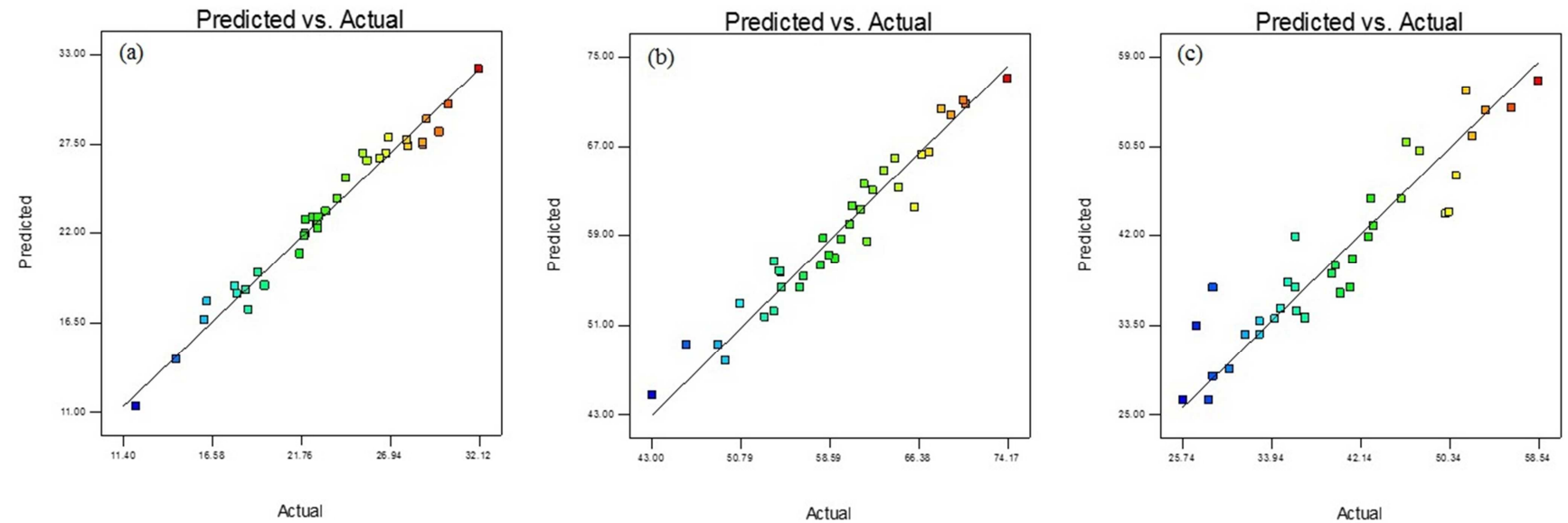

Figure 4. Predicted and actual values of data plotted for (a) Olefin, (b) Paraffin and (c) CO conversion.

\subsubsection{Effect of Parameters Via Model Graph}

Comparing the effect of all independent variables at a selected point in the design space is possible by perturbation plot. Although the perturbation plot indicates sensitive variables to response, it does not show interaction effects among them. The sharp slope or curvature of a variable imply that response is very sensitive to it, while relatively straight lines show that response is insensitive to it. According to

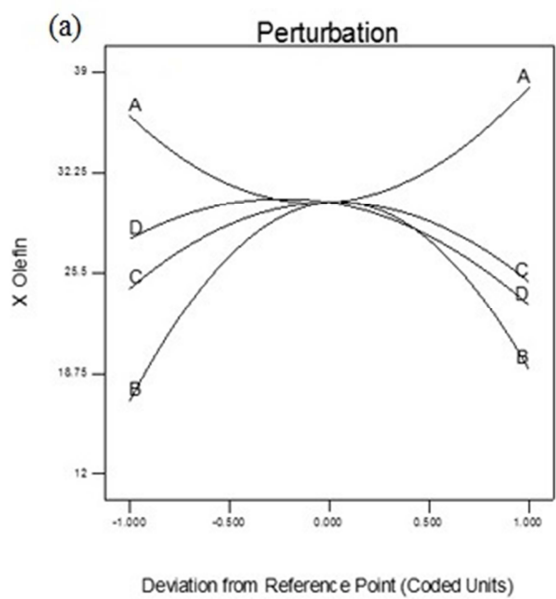

(b)

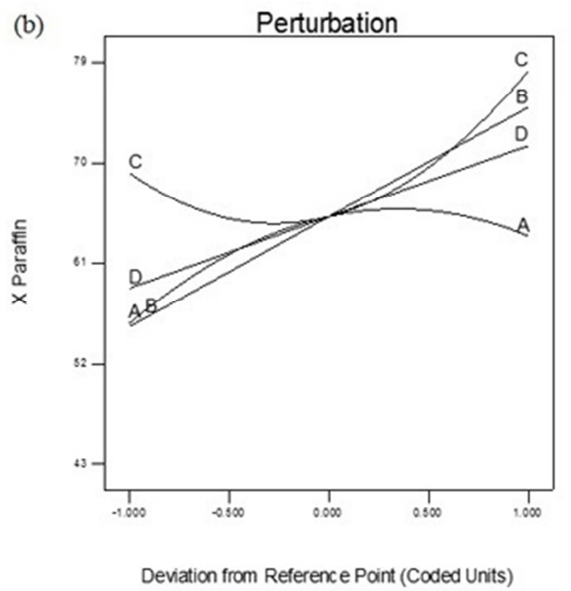

(c)

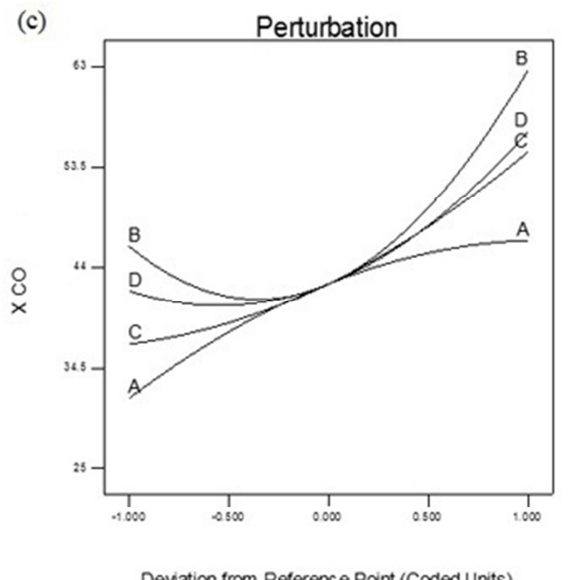

Figure 5. Perturbation plot for (a) $X_{1}=$ Olefin, (b) $X_{2}=$ Paraffin and (c) $X_{3}=C O$ conversion responses (A: amine concentration, $B$ : temperature, C: pressure, D: inlet $\mathrm{H}_{2} / \mathrm{CO}$ molar ratio).

In order to illustrate relationship between independent variables and effect of them on response, three dimensional
Figure 5, the sensitivity of olefin selectivity (a) decreases like $\mathrm{B}>\mathrm{C}>\mathrm{D}>\mathrm{A}$, so olefin is most sensitive to pressure variable (B). The sensitivity of paraffin selectivity (b) reduces based on $\mathrm{A}>\mathrm{B}>\mathrm{D}>\mathrm{C}$ therefore paraffin have the most sensitivity to amine concentration (A). As well as the sensitivity of catalyst activity to $\mathrm{CO}$ conversion (c) decreases according to $\mathrm{A}>\mathrm{C}>\mathrm{B}>\mathrm{D}$, so the result indicate that $\mathrm{CO}$ conversion has higher dependence on amine concentration (A). 
responses interpreted, which other variables kept fix. From Figures 6 and 7 determine that maximum value of response (a) achieves at average values $335^{\circ} \mathrm{C}$ of temperature and 3.5 bar of pressure. Thus, there is a maximum for olefin selectivity $\left(\mathrm{X}_{1}\right)$ at $3 \mathrm{D}$ surface plot. It is obvious that by increasing in both amine concentration and temperature, the selectivity to paraffin (b) increases. As well as it is indicated that the activity of synthesized nanocatalyst increases at higher pressure and amine concentration due to increase in CO conversion. (a)

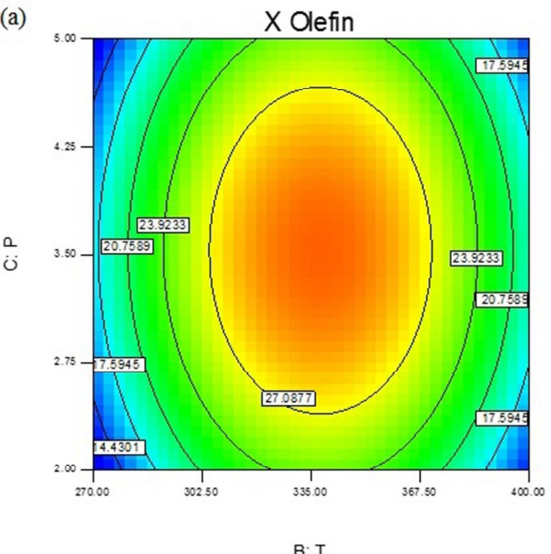

(b)

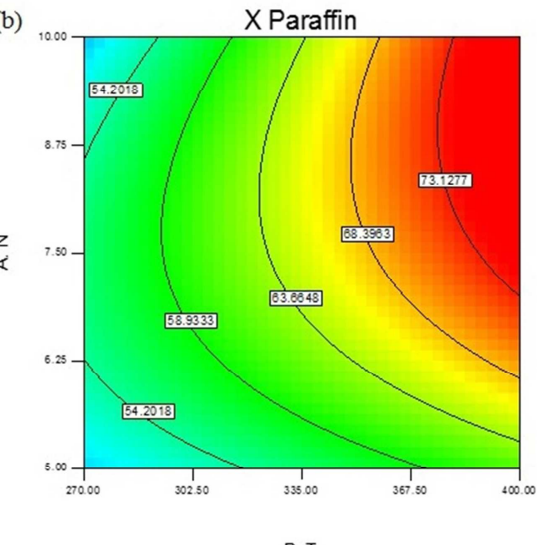

(c)

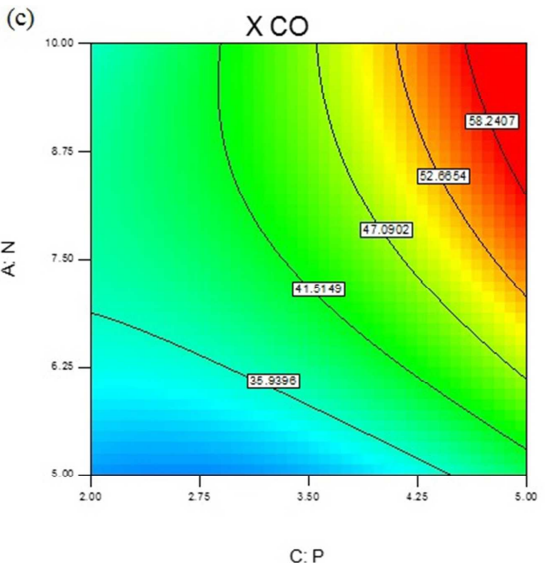

Figure 6. Contour plots, which illustrate the interaction effects between independent variables on responses, (a) Pressure and temperature, (b) Amine concentration and temperature, (c) Amine concentration and pressure.

(a)

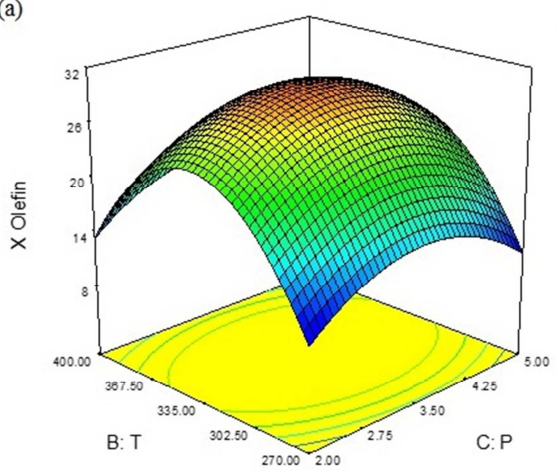

(b)

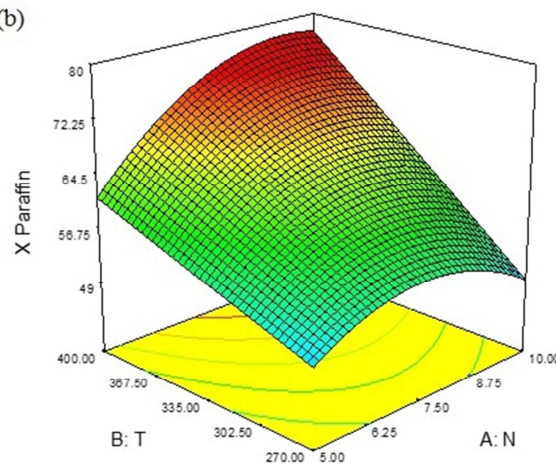

(c)

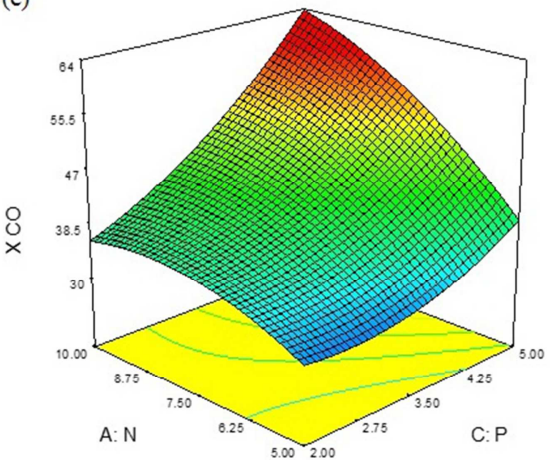

Figure 7. 3D surface plots, which illustrate interaction between independent variables on responses, (a) Pressure and temperature, (b) Amine concentration and temperature, (c) Amine concentration and pressure.

\subsubsection{Effect of Amine Concentration, Inlet $\mathrm{H}_{2} / \mathrm{CO}$ Molar Ratio and Pressure on Catalytic Performance}

The results indicate that by increasing in oleylamine concentration, both olefin selectivity and $\mathrm{CO}$ conversion increase, while paraffin selectivity decreases. There is relevance between oleylamine concentration and particle size, which is proven by XRD. As well as the smaller particle size, the stronger interactions between nanocatalyst, so it is caused higher catalyst activity. On the other hand, by decreasing in particle size, reduction of nanocatalyst became harder, which showed the TPR profiles shifted into higher temperatures. Also this result is proved by VSM that increasing in oleylamine concentration and smaller particle size caused lower residual magnetization (Mr) and higher coercivity $(\mathrm{Hc})$, which indicates powerful interaction between nanocatalysts that remain after leave external magnetization field out. The desirable response (maximum olefin selectivity and maximum $\mathrm{CO}$ conversion) achieved at lower inlet $\mathrm{H}_{2} / \mathrm{CO}$ molar ratio, which was expected. The lower $\mathrm{H}_{2} / \mathrm{CO}$ molar ratio, the higher olefin selectivity obtained. As the result showed higher catalyst activity achieved as a $\mathrm{CO}$ conversion at higher pressure. This is because of by increasing in pressure, the concentration of inlet gases increases, higher reaction rate and causes increase in $\mathrm{CO}$ conversion.

\subsubsection{Validation of Models}

In order to diagnostic the adequacy of obtained models, four plot have to be investigated, including; i) Normal Probability plot, ii) Internally Studentized Residuals versus predicted values plot, iii) Externally Studentized Residuals plot, and iv) Box-Cox plot. Figure 8 indicates that all residuals follow through a normal distribution. 


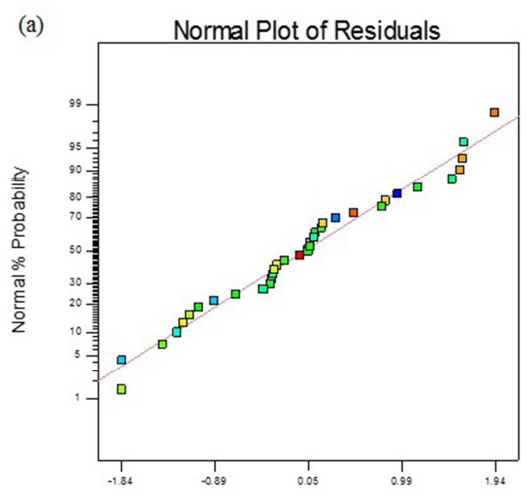

Intemally Studentized Residuals

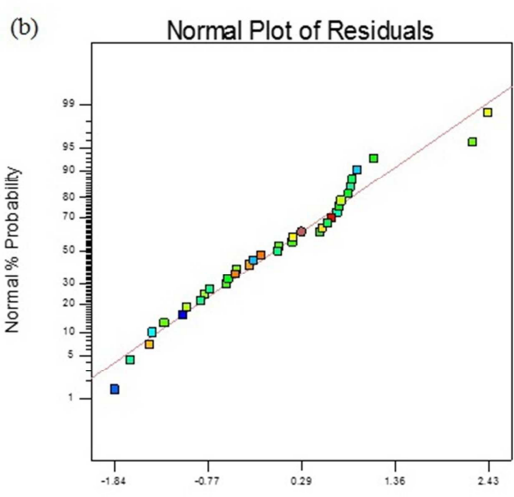

Intemally Studentized Residuals

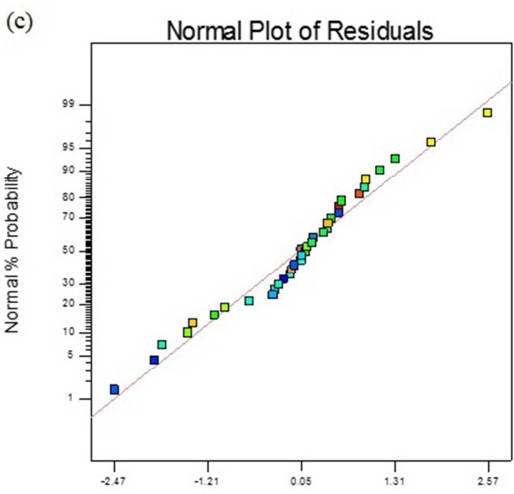

Intemally Studentized Residuals

Figure 8. Normal probability plot of residuals for (a) $X_{1}=$ olefin, (b) $X_{2}=$ paraffin, (c) $X_{3}=C O$ conversion.

Internally studentized plot shows residual values versus predicted values of responses. This plot investigates the hypothesis of constant variance by checking values to have constant error (between \pm 3 ). As Figure 9 indicates all plots have accidentally distribution, which represent residuals stay constant at all over the plots.
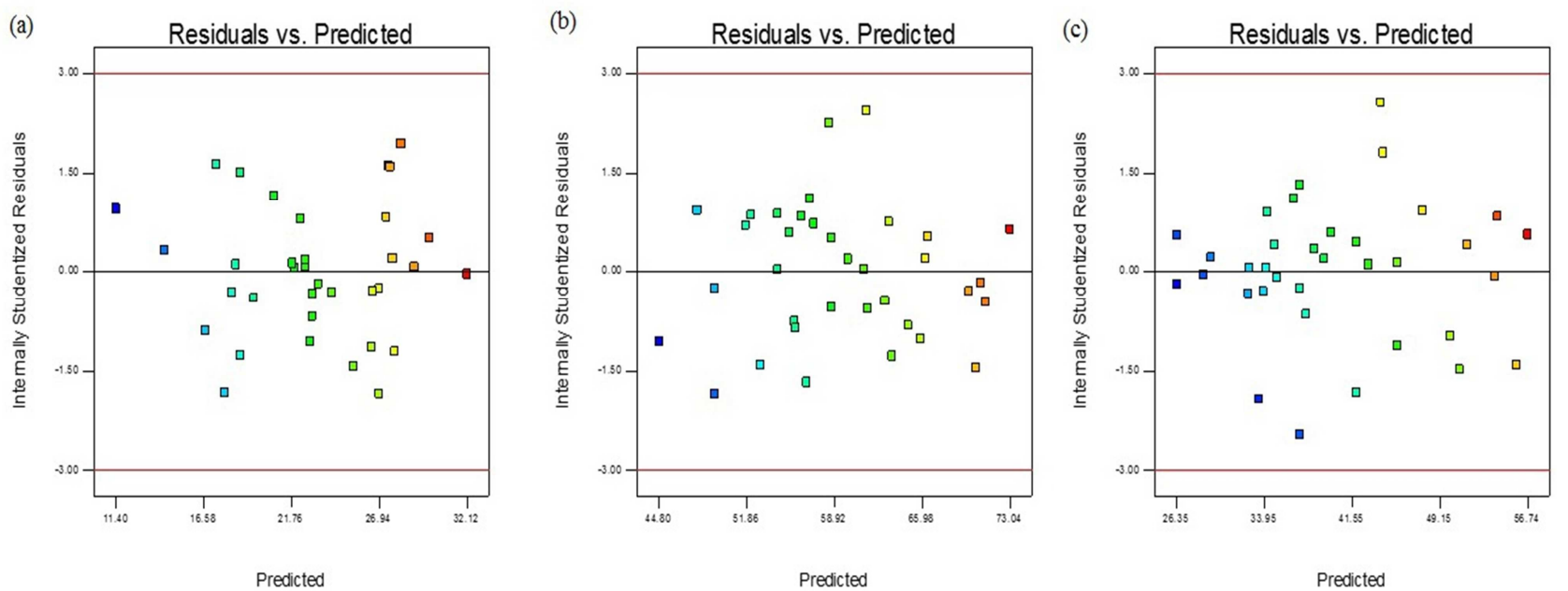

Figure 9. Internally studentized residuals plot of residuals versus predicted values, (a) $X_{1}=$ olefin, (b) $X_{2}=$ paraffin, (c) $X_{3}=C O$ conversion.

Externally studentized residuals plot demonstrates that the deviation value of standard deviation of actual value from predicted value after cross a point out. Figure 10 indicates that values are between $( \pm 3.5)$, so the residuals are not outliers.
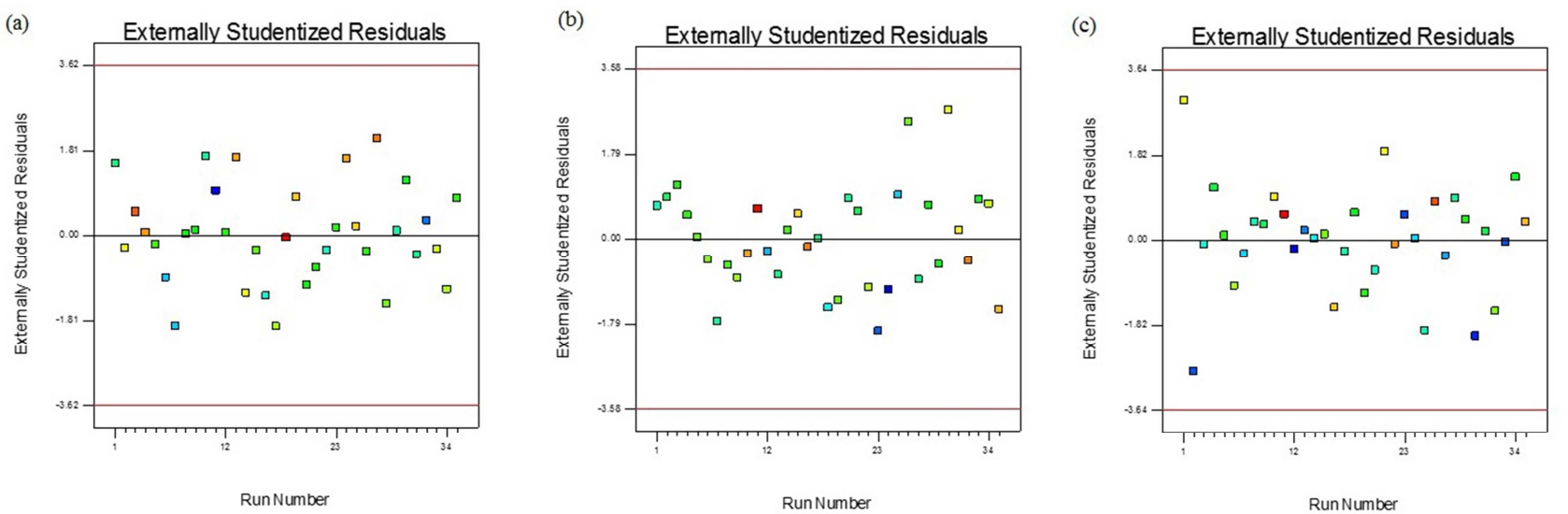

Figure 10. Externally studentized residuals plot for (a) $X_{1}=$ olefin, (b) $X_{2}=$ paraffin, (c) $X_{3}=$ CO conversion

Box-Cox plot is used to assist diagnosis the most suitable power transformation function in order to affect on response. The 
lowest point in Box-Cox plot shows (Figure 11) the best value of Landa, which minimum square residuals at transformed model created. When $\mathrm{max} / \mathrm{min}$ ratio of response value be higher than $>3$, there is more possibility to improve power function. Also confidence range at this value is shown.
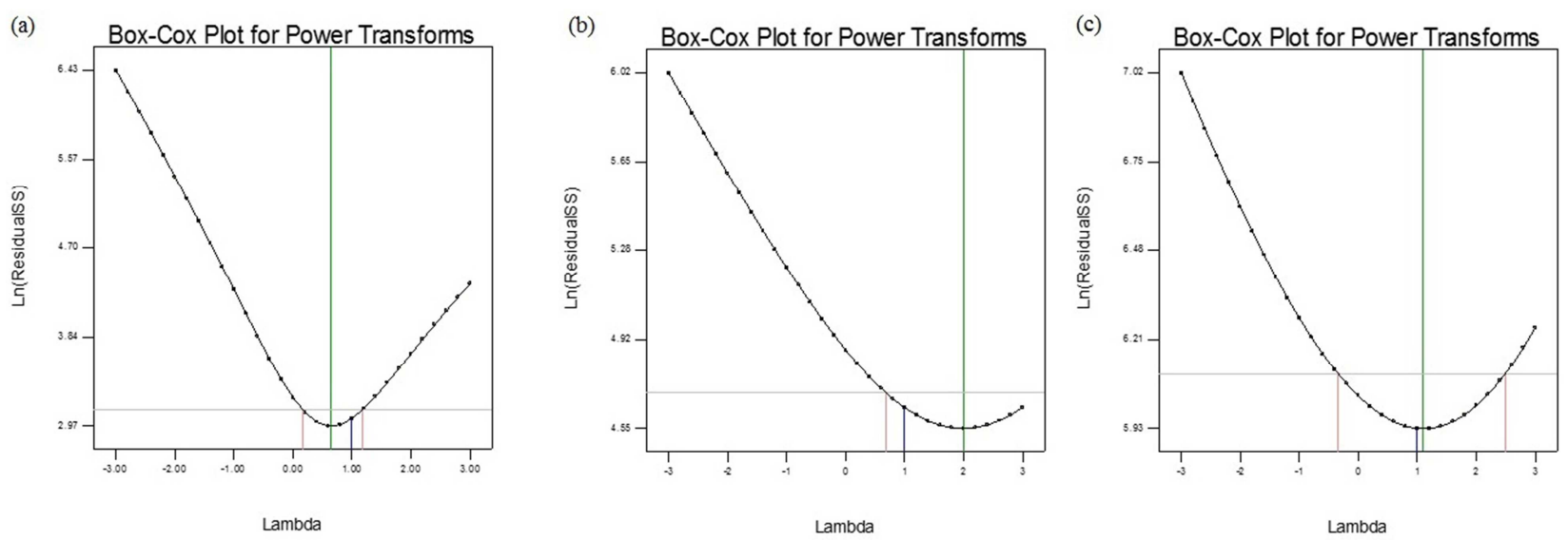

Figure 11. Box-Cox plot for power transforms of (a) $X_{1}=$ olefin, (b) $X_{2}=$ paraffin, (c) $X_{3}=$ CO conversion.

\subsubsection{Optimization}

The obtained models used to investigate optimization of all responses. The studied goal was to maximize $\mathrm{X}_{1}$ (olefin selectivity), $\mathrm{X}_{3}$ ( $\mathrm{CO}$ conversion, catalyst activity) and minimize $\mathrm{X}_{2}$ (paraffin selectivity), while all independent variables including $\mathrm{A}$ (amine concentration), B (temperature), $\mathrm{C}$ (pressure) and $\mathrm{D}$ (inlet $\mathrm{H}_{2} / \mathrm{CO}$ molar ratio) is chosen in range. Several solutions suggested by the software. The most desirable model in order to maximizing $X_{1}, X_{3}$ and minimizing $\mathrm{X}_{2}$ achieved at; 10 cc for amine concentration, $322.15^{\circ} \mathrm{C}$ for temperature, 3.93 bar for pressure and 1 for inlet $\mathrm{H}_{2} / \mathrm{CO}$ molar ratio. As well as olefin, paraffin selectivity and CO conversion for catalyst activity suggested 32.0139, 52.1847 and 42.889 respectively at desirability of 0.752 , which is shown in Figure 12. The predictability of the optimized model illustrated using experimental run. The result obtained 33.05 for olefin, 53.29 for paraffin and 42.56 for $\mathrm{CO}$ conversion, which indicates desirable confidence between predicted value and experimental.

Many researches had studied on selectivity of FischerTropsch synthesis, e.g Atashi et al [14] investigates modeling and optimizing of products through iron catalyst. Sun et al [15] illustrates optimization using response surface methodology using $\mathrm{SiO}_{2}$ bimetallic Co-Ni catalyst.
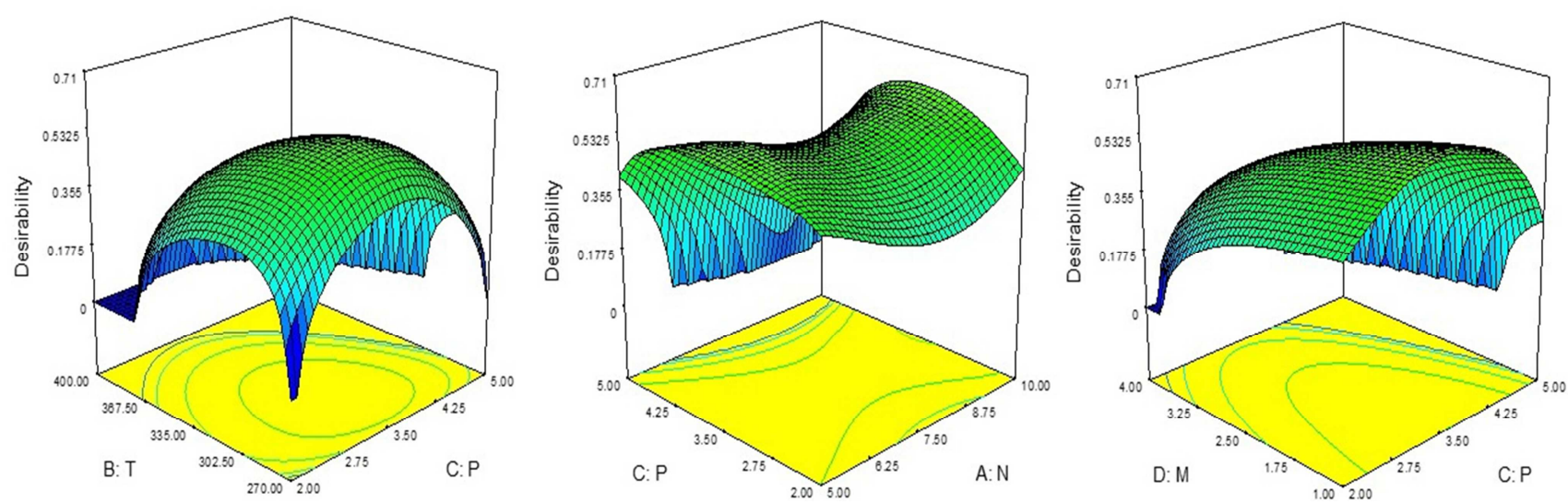

Figure 12. Optimum condition for maximum value of olefin and $\mathrm{CO}$ conversion and minimum value of paraffin achieved at $\left(\mathrm{N}=10 \mathrm{cc}, \mathrm{T}=322^{\circ} \mathrm{C}, P=3.93 \mathrm{bar}\right.$ and $M=1$ ).

\section{Conclusion}

Ternary Fe-Co-Ce nanocatalyst solvothermally synthesized and the effect of parameters on performance of nanocatalyst evaluated in detail. Amine concentration and pressure were both two significant factors in activity and selectivity of synthesized nanocatalyst in the Fischer-Tropsch synthesis. The statistical analysis of RSM applied to investigate individual, binary, interaction effects, modeling and optimizing of variables. The Fischer-Tropsch synthesis optimized at synthesis and operating parameters including amine concentration, temperature, pressure and feed $\mathrm{H}_{2} / \mathrm{CO}$ molar ratio. All responses optimized according to a simple linear model. There was a confidence agreement between predicted values and experimental. The results indicate that by increasing both amine concentration, pressure, and decreasing in temperature and inlet $\mathrm{H}_{2} / \mathrm{CO}$ molar ratio olefin 
selectivity and catalyst activity as CO conversion increases, while paraffin selectivity decreases. VSM analysis indicated that enhancing in oleylamine concentration resulted in ferromagnetic behavior of nanocatalysts, which alters from a soft to hard one. Magnetic measurements depicted that higher oleylamine concentration and smaller particle size leads to higher values of coercivity, while saturation magnetization and residual magnetization are independent of particle size. It was concluded from TPR profiles that oleylamine concentration by influencing on particle size results in increase at reduction temperature.

\section{Conflict of Interest}

All the authors do not have any possible conflicts of interest.

\section{Acknowledgements}

The authors would like to thank and appreciate the Ministry of Science \& Research, Research Department of Sistan \& Baluchestan University, the Iranian National Petrochemical Company (INPC) as well as Research Institute of Petroleum Industry (RIPI) for financial supports.

\section{References}

[1] A. Shamil Albazzaz, A. Ghassan Alsultan, S. Ali, Y. H. TaufiqYaq, M. A. Mohd Salleh, W. A. W. A. K. Ghani, Crbon Monoxide Hydrogenation on Activated Carbon Supported CoNi Bimetallic Catalysts Via Fischer-Tropsch Reaction to Produce Gasoline, Journal of Energy, Environmental \& Chemical Engineering, 3 (2018) 40-53.

[2] U. P. M. Ashik, A. Viswan, Sh. Kudo, J-I. Hayashi, Nanomaterials as Catalysts, Applications of Nanomaterials, 2018, https://doi.org/10.1016/B978-0-08-101971-9.00003-X.

[3] H. Pan, L. Wang, Sh. He, J. Wang, Improvement of Sol-gel Method and Influence of Calcination Conditions on Properties of $\mathrm{MnOx}-\mathrm{CeOx} / \mathrm{WO}_{3} / \mathrm{TiO}_{2}-\mathrm{ZrO}_{2}$ Catalyst, Science Discovery, 5 (2017) 463-468.

[4] M. Abdouss, M. Arsalanfar, N. Mirzaei, and Y. Zamani, "Effect of Drying Conditions on the Catalytic Performance, Structure, and Reaction Rates over the Fe-Co-Mn/MgO Catalyst for Production of Light Olefins," Bulletin of Chemical Reaction Engineering \& Catalysis, vol. 13, no. 1, pp. 97-112, Apr. 2018. https://doi.org/10.9767/bcrec.13.1.1222.97-112

[5] A. Guerrero-Ruiz, A. Sepulveda-Escribano, I. RodriguezRamos, Mangesium, vanadium and cerium oxides. Appl Catal A, 1994, 120, 71 .

[6] C. Perego, P. Villa, Catalyst preparation methods, Chapter 3, Catalysis Today 34 (1997) 281-305.

[7] M. Shakouri-Arani, M. Salavati-Niasari, Synthesis and characterization of wurtzite $\mathrm{ZnS}$ nanoplates through simple solvothermal method with a novel approach, J. Ind. Eng. Chem, 20 (2014) 3179-3185.

[8] S. Peng, C. Wang, J. Xie, S. Sun, Synthesis and stabilization of monodisperse Fe nanoparticles, J. Am. Chem. Soc, 128 (2006) 10676-10677.

[9] A. D. Ostrowski, E. M. Chan, D. J. Gargas, E. M. Katz, G. Han, P. J. Schuck, D. J. Milliron, B. E. Cohen, controlled synthesis and single-particle Imaging of Bright, Sub-10 nm Lanthanide-Doped Upconverting Nanocrystals, ACS Nano, 6 (2012) 2686-2692.

[10] Fermoso, J.; Gil, M. V.; Arias, B.; Plaza, M. G.; Pevida, C.; Pis, J. J.; Rubiera, F. Application of response surface methodology to assess the combined effect of operating variables on high-pressure coal gasification for H2-rich gas production. Int. J. Hydrogen Energy 2010, 35, 1191.

[11] Y. Zhang, L. Ma, T. Wang, X. Li, Synthesis of Ag promoted porous $\mathrm{Fe}_{3} \mathrm{O}_{4}$ microspheres with tunable pore size as catalysts for Fischer-Tropsch production of lower olefins, Catal. Commun, 64 (2015) 32-36.

[12] J. Tu, M. Ding, Y. Zhang, Y. Li, T. Wang, L. Ma, CH. Wang, $\mathrm{X}$. Li, Synthesis of $\mathrm{Fe}_{3} \mathrm{O}_{4}$-nanocatalysts with different morphologies and its promotion on shifting $\mathrm{C}_{5}{ }^{+}$hydrocarbons for Fischer-Tropsch synthesis, Catal. Commun, 59 (2015) 211-215.

[13] Gunaraj, V.; Murugan, N. Application of response surface methodologies for predicting weld base quality in submerged arc welding of pipes. J. Mater. Process. Technol. 1999, 88, 266.

[14] H. Atashi, F. Rezaeian, Modelling and optimization of Fischer-Tropsch products through iron catalyst in fixed-bed reactor, Int. J. Hyd. Eng.

[15] Y. Sun, J. Wei, J. Ping Zhang, G. Yang, Optimization using respoce surface methodology and kinetic study of FischerTropsch synthesis using $\mathrm{SiO} 2$ supported bimetallic $\mathrm{Co}-\mathrm{Ni}$ catalyst, J. Nat. Gas. Sci \& Eng. 28 (2016) 173-183. 